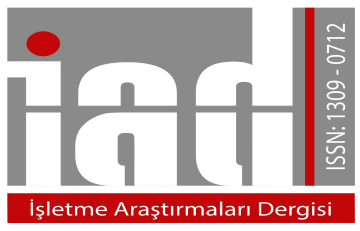

Journal Of

Business Research

Turk

www.isarder.org

\title{
Boredom at Work: A Research on Public Employees
}

\author{
Şeyda Nur SEÇKİN \\ İnönü University \\ Faculty of Economics and Administrative Sciences \\ Department of Business Administration \\ Malatya, Turkey \\ orcid.org/0000-0002-2313-1340 \\ seydaseckin@gmail.com
}

\begin{abstract}
This study aims to investigate the mediating effect of intention to turnover and the moderating role of organizational support on the relationship of work-related boredom and life satisfaction. Although work-related boredom is common in a wide variety of work settings, empirical researches are relatively limited. Besides, there does not exist any study on work-related boredom in domestic literature. Thus, it can be said that study findings may contribute to the understanding of work-related boredom and shed light on future studies that will be conducted in Turkish context. Study findings have shown that work-related boredom has a negative impact on life satisfaction and a positive impact on intention to turnover. In addition, the mediating effect of intention to turnover and the moderating role of organizational support on work-related boredomlife satisfaction relationship were found to be significant.
\end{abstract}

Keywords: work-related boredom, intention to turnover, life satisfaction, organizational support

\section{Introduction}

Boredom in the workplace has become widespread in a wide variety of work settings (Loukidou, Loan-Clarke and Daniels, 2009). Traditionally, it was considered as a function of monotonous and repetitive tasks but afterwards it was found that boredom also occur in mentally demanding environments (Cummings, Gao and Thornburg, 2016). Work-related boredom is a transient, emotional state and arises as a response to unchallenging or unstimulating work situations (Loukido et. al., 2009). Employees may feel bored time to time in the workplace; but also, feelings of boredom may become permanent and it can be experienced at a more global level (Van Hoof and Van Hooft, 2014,2017). Studies have shown that work-related boredom results in negative outcomes such as dissatisfaction (Lee, 1986), impaired performance (Fisher, 1991; Reijseger, et. al., 2013), counterproductive behavior (Bruursema et. al., 2011), depression (Wiesner, Windle and Freeman, 2005), work related injuries and accidents (Drory, 1982) etc. These negative outcomes affect not only employee well-being but 
also the organizational outcomes; thus, it is important to consider work-related boredom as a noteworthy emotional state affecting employee attitudes toward both work and the organization. On the other hand, work-related boredom has received little attention from contemporary researchers (Tsai, 2016). Despite its negative outcomes and being common in a wide variety of work settings, studies on work-related boredom in organizational research are relatively limited. In addition to this, there does not exist any study in domestic literature. Thus, it can be stated that findings may contribute to the understanding of work-related boredom and shed light on studies that will be conducted in future in Turkish context.

\section{Literature Review}

\subsection{Work-Related Boredom}

Work-related boredom can be defined as "a negative, affective motivational state of mind that results from a work environment that elicits little activity and provides little challenge and pleasure" (Reijseger, et. al., 2013:509). It is a transient, activityrelated emotional state and occurs when work situations or tasks are perceived as meaningless and unchallenging (Van Hoof and Van Hooft, 2017; Van Tilburg and Igou, 2012). Feelings of boredom in the workplace may arise temporarily but also may become permanent and can be experienced at a more global level (Van Hoof and Van Hooft, 2014:140). Bored employees fail to keep concentration on work, feel frustration and physical restlessness (Hill and Perkins, 1985) and also tend to display immediate withdrawal behaviors such as working slowly, dealing with non-work activities etc. (Van Hoof and Van Hooft, 2014; Van der Heijden, Schepers and Nijssen, 2012).

Qualitative underload; in other words, jobs which are simple, monotonous and repetitive are frequently mentioned as the main factor that lead employees to experience boredom (Fisher, 1991; Reijseger, et. al., 2013; Smith, 1981). This kind of jobs require little challenge and provide jobholders with low external stimulation and thus, they are emphasized as an underlying factor in boredom. On the other hand, studies (Prinzel and Freeman, 1997; Sawin and Scerbo,1995) have shown that boredom may also occur in mentally demanding environments especially in which continuous attention is required. Besides, in a qualitative study conducted by Fisher (1987), other job characteristics such as quantitative underload (to have nothing to do) and qualitative overload (too complex tasks) were found to be associated with boredom positively (Fisher, 1991).

Studies examining the antecedents of boredom have shown that lack of autonomy, social support from supervisor and coworkers (Reijseger, et. al., 2013); lack of skill variety and task identity (Bruursema, Kessler and Spector, 2001); unsupportive or unfriendly work environment (Fisher, 1993; Reijseger, et. al., 2013) are related to boredom positively. Individual differences were also found to play an important role on the frequency of experiencing work-related boredom. For instance, Farmer and Sundberg (1986) conceptualized boredom proneness as a specific personality trait and suggested that individuals high in this trait report higher levels of boredom. In addition, low level of conscientious (Sansone, et. al., 1999), high level of extraversion, openness to experience (Mäkikangas et al., 2015) and intellectual capacity (Drory, 1982) were found to be the other individual factors associated with work-related boredom positively. 
The vast majority of the studies have shown that work-related boredom has negative consequences. Boredom affects employees' attitudes toward their jobs negatively and frequent feelings of boredom result in a decrease in both job satisfaction and performance (Fisher, 1991; Reijseger, et. al., 2013; Lee, 1986). Researchers have found that boredom is also associated with intention to turnover (Kass et al., 2001; Reijseger, et. al.,2013); counterproductive work behavior (Bruursema et. al., 2011); withdrawal (Spector et al., 2006); work-related injuries and accidents (Drory, 1982; Frone, 1998) positively and with organizational commitment (Kass et al., 2001; Reijseger, et. al., 2013) negatively. Furthermore, studies have shown that boredom has a negative effect on employee well-being. It was found that boredom is associated with health problems such as cardiovascular disease (Britton and Shipley, 2010); depression (Wiesner, Windle and Freeman, 2005); depressed mood (Van Hoof and Van Hooft, 2016) positively; and with general life satisfaction (Johansson, Aronsson and Lindstrom, 1978; Smith, 1981), quality of life (Watten et. al., 1995) negatively.

According to Cummings, Gao and Thornburg, (2016:286); work-related boredom results in behavioral changes. Authors classified these behavioral changes in three categories: (a) task-unrelated thought, (b) other task engagement and (c) changing task engagement. When employees experience boredom, they fail to focus on work and they may begin to daydream or think task-unrelated issues. Task-unrelated thought; in other words, mind wandering, is used by employees in order to cope with boredom. Second type of behavior, other task engagement, can also be labeled as distraction and displayed as a reaction to boredom. Employees may be distracted either by a task which is related their current job or by non-work activities such as reading magazines, surfing on the internet etc. The last one, changing the primary task engagement, involves increasing the complexity of the task, refocusing attention on the task and/or taskrelated imagination. Authors define changing task engagement as a task-focused coping strategy because by this strategy, employees can be able to focus and concentrate on their primary tasks.

Given the fact that most of the employees spend majority of their time in the workplaces, it can be said that experiencing boredom permanently at work would affect employees' life satisfaction negatively. Studies (Johansson et. al., 1978; Smith, 1981, Watten et. al.1995, Wiesner et. al., 2005 etc.) have shown that work-related boredom is related to depression, frustration, physical restlessness, depressive mood positively and results in a lower level of life quality and satisfaction. Furthermore, Van Hoof and Van Hooft (2016) found boredom and its negative affective consequences to spill over outside the work and affect one's other domains of life negatively. Thus, it is hypothesized as:

$\mathbf{H}_{1}$ : Work-related boredom is associated with life satisfaction negatively.

\subsection{The Mediating Effect of Intention to Turnover on The Relationship of Work-Related Boredom And Life Satisfaction}

Since work-related boredom arises as a negative response to uninteresting work situations (Fisher, 1991), it can be expected that it would affect jobholders' attitudes regarding to their works negatively and their overall satisfaction with their jobs would diminish. Studies have shown that work-related boredom results in a decrease in 
intrinsic motivation (Gkorezis and Kastritsi, 2017), need satisfaction (Van Hoof and Van Hooft, 2017), job satisfaction and an increase in intention to turnover (Mann, 2017; Kass et.al., 2001). So, the more employees experience boredom the more they may intend to quit the job. This line of reasoning can also be supported by work event theory (Weiss and Cropanzano, 1996) and the theory of planned behavior (Ajzen, 1991). According to work event theory, certain work events occur as a result of the work environment characteristics and lead employees to develop affective responses (for instance, in this case boredom). These affective responses, afterwards, shape one's work attitudes (for instance, in this case negative attitudes about job as a result of being bored permanently at work). The theory of planned behavior, on the other hand, considers attitudes as the core elements and suggests that attitudes affect one's subsequent intentions and behaviors. Therefore, it can be expected that experiencing boredom permanently at work may result in developing negative attitudes toward job and these negative attitudes may trigger intention to turnover. Based on this line of reasoning, it is hypothesized as:

$\mathbf{H}_{2}$ : Work-related boredom is associated with intention to turnover positively.

According to Fisher (1991:28), unstimulating work environments create free mental time for employees to think about quitting the job. Any alternative job becomes more attractive in the eyes of the employee and it leads to an increase in intention to turnover. However, going to a new job or just leaving without finding another is not an easy task. It brings uncertainty and ambiguity to one's life. Either job change or simply quitting may entail one to deal with necessary rearrangements or readjustment in life; and in order to be settled down again, one should spend time and effort (Mitchell, Holtom and Lee, 2001). So, it can be expected that beside being bored in the workplace; uncertainty, ambiguity and hurdles one may face when he/she intends to quit may have a negative effect on one's life satisfaction. Thereby, it is hypothesized as:

$\mathbf{H}_{3}$ : Intention to turnover mediates the relationship of work-related boredom and life satisfaction.

\subsection{The Moderating Role Of Organizational Support}

Organizational support can be defined as the subjective evaluations of the employees' regarding to what extent the organization values their contributions and cares about their well-being (Rhoades and Eisenberger, 2002). According to social exchange theory (Blau, 1964) and norm reciprocity (Gouldner, 1960), employees are in both economic and social exchange relationships with the organization and these exchanges shape employee attitudes. So, it can be expected that the degree of organizational support perceived may differentiate the strength of relationship of boredom and intention to turnover. If one experiencing work-related boredom believes that organizational support he/she takes is high; he/she may develop less negative attitudes toward work and thus, may less intend to quit the job. Otherwise, in addition to experiencing boredom at work; also believing that organization fails to provide support would be more frustrating for the employee so that he/she would more intend to leave the job. Thus, it is hypothesized as:

$\mathbf{H}_{4}$ : Organizational support perceived moderates the relationship of work-related boredom and intention to turnover. 


\section{Methodology}

\subsection{Research Model and Hypotheses}

Based on theory and previous study findings, research model and hypotheses developed are presented below:

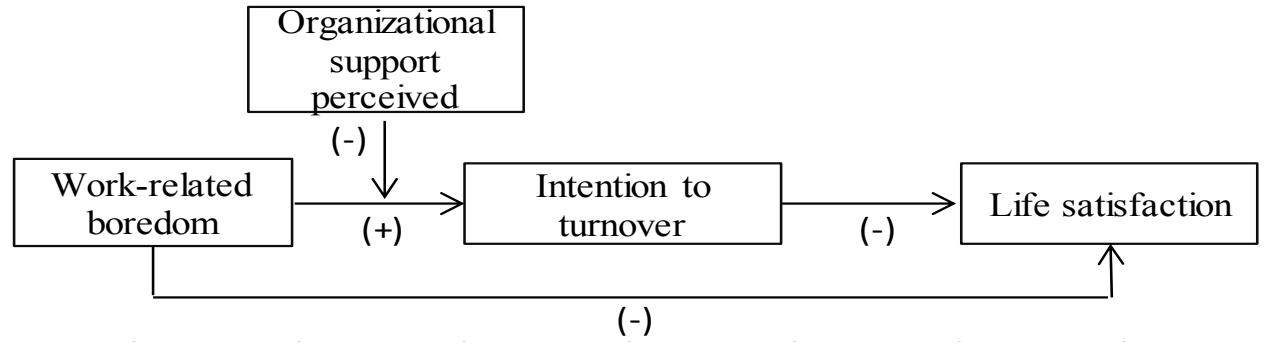

Figure 1: Research Model

$\mathbf{H}_{1}$ : Work-related boredom is associated with life satisfaction negatively.

$\mathbf{H}_{2}$ : Work-related boredom is associated with intention to turnover positively.

$\mathbf{H}_{3}$ : Intention to turnover mediates the relationship of work-related boredom and life satisfaction.

$\mathbf{H}_{4}$ : Organizational support perceived moderates the relationship of work-related boredom and intention to turnover.

\subsection{Research Method and Sample}

Field research was conducted on 189 public employees working in three different public organizations in Malatya. Study sample was limited to public employees because when compared to employees in private sector, they are more likely to work on monotonous and repetitive tasks which are frequently emphasized as one of the main predictors of work-related boredom (e.g., Fisher, 1993; Loukidou et al., 2009; Smith, 1981). Survey method was used and data collection was performed by convenience sampling. In order to test the hypotheses; reliability, confirmatory factor, correlation and regression analyses were conducted.

Descriptive statistics of the sample indicate that slightly more than half of the participants were male $(\% 54,4)$ and majority of the respondents were married $(\% 82,3)$. The proportion of the participants holding a bachelor degree was $\% 82,7$; master degree was $\% 15,8$ and doctorate degree was $\% 2,5$. Of the respondents $\% 10,1$ was under the age of 30 . $\% 22,1$ was between $30-34$; $\% 22,8$ was between $35-39$ and $\% 23,4$ was between 40-44 and finally \%21,6 was between 45-49. The distribution of the respondents by organizational tenure was: fewer than 3 years: $(\% 19,5) ; 3$ to 8 years: $(\% 17,9)$; 9 to 14 years: $(\% 23,1)$ and 15 years and more: $(\% 39,5)$. In brief, descriptive statistics of the sample indicates that more than half of the participants were male; aged between 35-49; worked in their current organizations for minimum 9 years; majority of them were married and held a bachelor degree. 


\subsection{Measures}

Work-related boredom was measured by a 5-item unidimensional instrument used in Van Hoof and Van Hooft (2017). It was originally developed by Lee (1986). Sample items include: "I often get bored with my work", "The time seems to go by slowly when I'm at work" etc. For measurement of organizational support, short form of organizational support instrument was used. It was developed by Eisenberger et. al. (1986) consisting of 16 items (e.g., "The organization strongly considers my goals and values", "The organization tries to make my job as interesting as possible"). Intention to turnover was measured by 3 items developed by Mobley et. al. (1978). Finally, participants' life satisfactions were assessed by 5 items (e.g., "I am satisfied with my life", "In most ways, my life is close to my ideal") developed by Diener, Emmons, Larsen, and Griffin (1985). All measures were rated on a 5-point Likert scale from 1 (strongly disagree) to 5 (strongly agree).

Before hypotheses testing, confirmatory factor analysis was conducted to validate the factorial structures of the measures. First-order confirmatory factor analyses were performed for work-related boredom, life satisfaction and organizational support. Results of the analyses revealed that unidimensional structures of each measure were validated. Fit indices of work-related boredom $(\chi 2 / \mathrm{df}=2,714 ; \mathrm{RMSEA}=0,072$; $\mathrm{TLI}=0,976$; $\mathrm{CFI}=0,988)$; life satisfaction $(\chi 2 / \mathrm{df}=1,865 ; \mathrm{RMSEA}=0,051 ; \mathrm{TLI}=0,992$; $\mathrm{CFI}=0,996)$ and organizational support $(\chi 2 / \mathrm{df}=2,051 ; \mathrm{RMSEA}=0,057 ; \mathrm{TLI}=0,987$; $\mathrm{CFI}=0,996)$ were found to be within the recommended ranges (i.e., RMSEA $<0,08$; GFI, TLI and CFI > 90; Byrne, 2010). All items were loaded onto their respective factors and higher than 0,5 . In order to evaluate the distinctiveness of the measures, fit indices of the measurement model were also examined. Results of the confirmatory factor analysis revealed an acceptable fitting measurement model $\left(\chi^{2} / \mathrm{df}=3,055\right.$; $\mathrm{RMSEA}=0,079$; TLI $=0,934 ; \mathrm{CFI}=0,953)$. In order to evaluate the potential influence of common method variance, one factor model was analyzed and results revealed that one factor model was not validated. Total variance explained by single factor was found as $\% 18,71$. Finally, Cronbach's alpha coefficients of the measures were found to be within the interval of $0,908-0,955$ indicating that measures used in the study were reliable.

\section{Findings}

Means, standard deviations and correlation coefficients of the study variables are presented in Table 1:

Table 1: Descriptive Statistics and Correlation Coefficients

\begin{tabular}{lcccccc}
\hline Variables & Mean & SD & 1 & 2 & 3 & 4 \\
\hline 1. Work-related boredom & 2,760 & 1,145 & - & & & \\
2. Intention to turnover & 2,269 & 1,351 &, $653^{* *}$ & - & & \\
3. Org. support perceived & 2,160 & 1,206 &,$- 684^{* *}$ &,$- 562^{* *}$ & - & \\
4. Life satisfaction & 3,658 & 0,963 &,$- 685^{* *}$ &,$- 609 * *$ &, $729 * *$ & - \\
\hline$* * * \mathrm{p}<0,001 ; * \mathrm{p}<0,01 ; * \mathrm{p}<0,05$ & & & & &
\end{tabular}

According to Table 1, zero-order correlation results are in the expected direction. Work-related boredom correlates with intention to turnover positively $(r=, 653 ; p<0,01)$; and with life satisfaction negatively $(r=-, 685 ; \mathrm{p}<0,01)$. Beside this, intention to turnover 
is associated with life satisfaction and organizational support perceived in negative direction [ $(\mathrm{r}=-, 609 ; \mathrm{p}<0,01) ;(\mathrm{r}=-, 562 ; \mathrm{p}<0,01)$ respectively].

A series of hierarchical regression analyses were performed to test the relationship of workplace boredom, intention to turnover and life satisfaction. Demographic variables were determined as a control group (dummy variables: female:1, male:0; married:1, single:0) and entered at the first step since previous research findings indicate an association of these variables with intention to turnover and life satisfaction. Results are presented in Table 2:

Table 2. Hierarchical Regression Analysis

\begin{tabular}{lcccl}
\hline & \multicolumn{2}{c}{ Intention to Turnover } & \multicolumn{2}{c}{ Life Satisfaction } \\
\hline Constant & Beta & S.E & Beta & S.E \\
Age & 3,105 & $(, 230)^{* * *}$ & 2,834 & $(, 177)^{* * *}$ \\
Gender &, 037 & $(, 075)$ &,- 002 & $(, 058)$ \\
Marital status &, 275 & $(, 098)^{* *}$ &,- 303 & $(, 075)^{* * *}$ \\
Education &, 049 & $(, 032)$ &, 033 & $(, 052)$ \\
Tenure &, 022 & $(, 014)$ &,- 008 & $(, 041)$ \\
$\mathrm{R}^{2} / \Delta \mathrm{R}^{2}$ &,- 491 & $(, 090)^{* * *}$ &, 226 & $(, 069)^{* *}$ \\
&, 160 &, 160 &, 098 &, 098 \\
Work-related boredom & & & & \\
Intention to turnover &, 737 & $(, 054)^{* * *}$ &,- 458 & $(, 044)^{* * *}$ \\
$\mathrm{R}^{2} / \Delta \mathrm{R}^{2}$ & & &,- 179 & $(, 039)^{* * *}$ \\
\hline p $<0,05 ; * * \mathrm{p}<0,01 ; * * \mathrm{p}<0,001 ;$ Beta: unstandardized coefficient; S.E: standard error &, 541 &, 443
\end{tabular}

Results of the regression analysis show that among the demographic variables only gender and organizational tenure has a significant effect on intention to turnover. As it can be seen in Table 2, females when compared to males are more likely to intend to turnover $(B=, 275 ; p<0,01)$ and less satisfied with their lives $(B=-, 303 ; p<0,001)$. Organizational tenure, on the other hand, has a negative effect on intention to turnover $(B=-, 491 ; p<0,001)$ and a positive effect on life satisfaction $(B=, 226 ; p<0,01)$.

According to Table 2, work-related boredom has a positive effect on intention to turnover and a negative effect on life satisfaction $[(\mathrm{B}=, 737 ; \mathrm{p}<0,001) ; \quad(\mathrm{B}=-, 458$; $\mathrm{p}<0,001)$, respectively]. Thus, $\mathrm{H}_{1}$ and $\mathrm{H}_{2}$ are supported. In addition, intention to turnover was found to have a negative effect on life satisfaction $(B=-, 179 ; p<0,001)$.

In order to determine whether intention to turnover mediates the perceived workplace boredom and life satisfaction relationship bootstrapping method was used and the confidence interval was set at $\% 95$ by using PROCESS Macro 2.16 Model 4. Indirect effect of work-related boredom on life satisfaction through intention to turnover is presented in Table 3:

Table 3. The Indirect Effect of Work-Related Boredom on Life Satisfaction through Intention to Turnover

\begin{tabular}{lcccc}
\hline & Indirect Effect & \multicolumn{2}{c}{ Bootstrap CI= \%95 } \\
\hline Mediator & Beta & Boot SE & Boot LLCI & Boot ULCI \\
\hline Intention to turnover &,- 1430 &, 0382 &,- 2195 &,- 0694 \\
\hline $\begin{array}{l}\text { Beta: unstandardized coefficient; CI: confidence interval; Boot SE: bootstrap standard error; Boot LLCI: lower limit } \\
\text { of the bootstrap confidence interval; Boot ULCI: upper limit of the bootstrap confidence interval }\end{array}$
\end{tabular}


According to Table 3, the indirect effect of workplace boredom on life satisfaction through intention to turnover is -, 1430 and different from zero by a bias-corrected bootstrap confidence interval based on 10,000 bootstrap samples. In other words, the relationship of workplace boredom and life satisfaction is mediated by intention to turnover. Thereby, $\mathrm{H}_{3}$ is supported.

In order to determine whether respondents' organizational support perceptions moderate the work-related boredom and intention to turnover relationship, hierarchical moderated regression analysis was performed. Before analysis, all the independent and dependent variables were standardized. Control variables were entered at first; independent variables were entered at the second step and finally, the interaction term (simple product of workplace boredom and organizational support) was entered to the regression. Results are presented in Table 4:

Table 4. Hierarchical Moderated Regression Analyses

\begin{tabular}{lcl}
\hline & \multicolumn{2}{c}{ Intention to Turnover } \\
\hline Constant & Beta & S.E \\
Age &, 619 & $(, 170)^{* * *}$ \\
Gender &, 028 & $(, 056)$ \\
Marital status &, 203 & $(, 072)^{* *}$ \\
Education &, 039 & $(, 032)$ \\
Organizational tenure &, 042 & $(, 034)$ \\
$\mathrm{R}^{2} / \Delta \mathrm{R}^{2}$ &,- 363 & $(, 066)^{* * *}$ \\
&, 160 &, 160 \\
Work-related boredom & & $(, 054)^{* * *}$ \\
Organizational support perceived &, 469 & $(, 054)^{* * *}$ \\
$\mathrm{R}^{2} / \Delta \mathrm{R}^{2}$ &,- 192 &, 350 \\
&, 510 & $(, 040)^{* *}$ \\
Work-related boredomXorganizational support perceived &,- 131 &, 016 \\
$\mathrm{R}^{2} / \Delta \mathrm{R}^{2}$ &, $526 /$ &
\end{tabular}

As depicted in Table 4, interaction term is significant for the relationship of workrelated boredom and intention to turnover $(B=-, 131 ; p<0,01)$. In order to explore the nature of this interaction, further simple slopes were computed using high and low levels of the moderator (1SD above and below the mean) (Aiken and West, 1991). Results show that work-related boredom has a stronger positive effect on intention to turnover for employees whose organizational support perceptions are low $(B=, 586$; $\mathrm{p}=0,000$ ). For employees whose organizational support perceptions are high, on the other hand, the positive impact of work-related boredom on intention to turnover is lower $(\mathrm{B}=, 323 ; \mathrm{p}=0,000)$. As a result, $\mathrm{H}_{4}$ is supported.

Whether the indirect effect of workplace boredom on life satisfaction through intention to turnover varies depending on the organizational support perceived was analyzed by using PROCESS Macro 2.16 Model 7. Results are presented in Table 5: 
Table 5: Indirect Effect of Work-Related Boredom on Life Satisfaction Through Intention to Turnover

\begin{tabular}{lccc}
\hline & \multicolumn{2}{c}{ Life Satisfaction } \\
\hline $\begin{array}{l}\text { Organizational Support } \\
\text { Perceived }\end{array}$ & Indirect Effect & \multicolumn{2}{c}{ Bootstrap CI=\%95 } \\
\hline & Beta & Boot LLCI & Boot ULCI \\
\hline Very Low &,- 1506 &,- 2271 &,- 0828 \\
Low &,- 1407 &,- 2105 &,- 0777 \\
Medium &,- 1013 &,- 1573 &,- 0585 \\
High &,- 0849 &,- 1413 &,- 0472 \\
Very High &,- 0685 &,- 1259 &,- 0320 \\
\hline
\end{tabular}

Beta: unstandardized coefficient; CI: confidence interval; Boot SE: bootstrap standard error; Boot LLCI: lower limit of the bootstrap confidence interval; Boot ULCI: upper limit of the bootstrap confidence interval

According to Table 5, the indirect effect of workplace boredom on life satisfaction through intention to turnover decreases as respondents' organizational support perceptions increase (CI: 95\%, BootLLCI $=-, 2271$; BootULCI $=-, 0320)$. In other words, when boredom at the workplace increases, intention to turnover also increases resulting in a decrease in life satisfaction. However, as respondents' organizational support perceptions increase; the negative impact of workplace boredom on life satisfaction via intention to turnover diminishes.

\section{Discussion}

Study findings have shown that work-related boredom affects intention to turnover positively and life satisfaction negatively. This result is consistent with the previous research findings that have shown a positive relationship between work-related boredom and intention to turnover (Kass et. al., 2001; Reijseger, et.al., 2013) and a negative relationship of boredom and life satisfaction (Johansson et. al., 1978; Smith, 1981). Besides, intention to turnover was found to mediate the relationship of workrelated boredom and life satisfaction. The more work-related boredom employees experience, the more they intend to leave the job, and the less they are satisfied with their life. This result can be interpreted as that employees experiencing work-related boredom may develop negative attitudes toward their jobs and more intend to quit the job. But finding a new job or just simply quitting without finding another is not an easy task. Both of them bring uncertainty and ambiguity in one's life. Thus, the mediating effect of intention to turnover and its negative impact on life satisfaction can be viewed as an expected result.

The moderating effect of organizational support on the relationship of workrelated boredom and intention to turnover was found to be significant. For employees believing that they are supported by the organization at a high level, the positive effect of work-related boredom on intention to turnover is low. For employees whose organizational support perceptions are low, work-related boredom affects intention to turnover more positively. This result can be explained as that in addition to being bored permanently at work, one's believing that he/she is lack of organizational support demoralize employee more; and thus, he/she may more intend to quit the job. In case of high organizational support perceived, experiencing work-related boredom may result in less negative attitudes and thus, one may less intend to quit the job.

Study findings have also shown that the indirect effect of work-related boredom on life satisfaction through intention to turnover differs depending on the respondents' 
organizational support perceptions. As perceived organizational support increases, the negative indirect impact of work-related boredom on life satisfaction via intention turnover diminishes. So, organizational support can be viewed as an effective factor which mitigates the negative impact of work-related boredom on life satisfaction.

Due to the fact that work-related boredom has a negative effect on both individual and organizational outcomes, it is important for organizations to take boredom into account as an organizational problem. In order to eliminate it or, at least to mitigate, redesigning jobs in such a way that employees can fulfill their potential, develop new skills or have more learning opportunities can be beneficial. Thereby, employees can be motivated intrinsically and the experience of boredom may unlikely to arise. In addition, organizational support can be used as an intervention tool to attenuate workrelated boredom. Treating employees fairly and in a supportive manner, building open communication channels in the organization, recognizing and rewarding employee performance, providing opportunities for personal growth and development can increase organizational support perception of the employees. When bored employees believe that they are supported by the organization, they may develop less negative attitudes toward both work and the organization. Otherwise, in addition to experiencing boredom, believing that organization fail to provide support would trigger employees' negative attitudes toward work and thus, detrimental effects of boredom would be more intense. In addition to this, since individual differences also play an important role in the degree of experiencing work-related boredom, it can be recommended that during the selection and recruitment periods, the degree of boredom proneness, openness to experience, stimulus seeking and intellectual capacity of the job candidates should be assessed and job placements should be made (especially for relatively more monotonous tasks) taking into account these individual differences.

Although study findings may contribute to the understanding of work-related boredom and its negative outcomes, there exists a number of limitations of the study. First, the data were collected from a single source in a single time period. Therefore, inferences of causality cannot be established. Although study findings indicate that work-related boredom affects life satisfaction negatively, it is also possible that respondents who are not satisfied with their life may tend to evaluate happenings at work more negatively and experience a higher degree of boredom in the workplace. Second limitation of the study is the potential influence of common method variance. Although one factor model was not validated and total variance explained by single factor was small, any doubts about the potential influence of common method variance would be eliminated by longitudinal researches. Third, the sample of the study consists of public employees working in three public organizations; thus, the generalizability of the findings is limited. So, it can be recommended to replicate the study in other organizational contexts and/or occupational groups in order to have a better understanding of work-related boredom and its adverse effects. For future research, individual differences such as need for growth, conscientiousness, work goal orientation and achievement need can be examined as potential variables that may affect employee reactions to work-related boredom. Also, personal characteristics such as openness to experience, boredom proneness and extraversion can be taken into account to determine to what extent these personal characteristics explain the variation in degree of experiencing boredom at work. 


\section{References}

Ajzen, I. (1991). The theory of planned behavior. Organizational Behavior and Human Decision Processes, Vol. 50, 179-211.

Blau, P.(1964). Exchange and power in social life, New York:Free Press.

Britton, A., Shipley, M. J. (2010). Bored to death? International Journal of Epidemiology, Vol.39, 370-371.

Bruursema, K., Kessler, S. R., Spector, P. E. (2011). Bored employees misbehaving: The relationship between boredom and counterproductive work behavior. Work \& Stress, Vol.25, No.2, 93-107.

Byrne, B. M. (2010). Structural Equation Modeling with AMOS: Basic Concepts, Applications, and Programming. Routledge Taylor \& Francis Group, $2^{\text {nd }}$ edition, New York.

Cummings, M. L., Gao, F., Thornburg, K. M. (2016). Boredom in the Workplace: A New Look at an Old Problem. Human Factors, Vol.58, No.2, 279-300.

Drory, A. (1982). Individual differences in boredom proneness and task effectiveness at work. Personnel Psychology, Vol.35, 141-151.

Eisenberger, R., Huntington, R., Hutchison, S., Sowa, D. (1986). Perceived Organizational Support. Journal of Applied Psychology, Vol.71, No.3, 500-507.

Farmer, R., Sundberg, N.D. (1986). Boredom proneness: The development and correlates of a new scale. Journal of Personality Assessment, Vol.50, 4-17.

Fisher, C.D. (1987). Boredom: Construct, causes and consequences. Technical Report ONR-9, Texas A\&M University.

Fisher, C. D. (1991). Boredom at work: a neglected concept. School of Business $\begin{array}{lll}\text { Discussion } & \text { Papers, } & \text { Paper }\end{array}$ http://epublications.bond.edu.au/discussion_papers/19,

Gkorezis, P., Kastritsi, A. (2017). Employee expectations and intrinsic motivation: work-related boredom as a mediator. Employee Relations, Vol.39, Issue 1, 10011.

Gouldner, A. W. (1960). "The norm of reciprocity: A preliminary statement". American Sociological Review, Vol.25, 161-178.

Hill, A.B., Perkins, R.E. (1985). Towards a model of boredom. British Journal of Psychology, Vol.76, 235-240.

Johansson, G., Aronsson, G., Lindstrom, B. O. (1978). Social psychological and neuroendocrine stress reactions in highly mechanized work. Ergonomics, Vol.21, 583-599.

Kass, S.J., Vodanovich, S.J., Callender, A. (2001). State-boredom proneness: Relationship to absenteeism, tenure, and job satisfaction. Journal of Business and Psychology, Vol.16, 317-327.

Lee, T.W. (1986). Toward the development and validation of a measure of job boredom. Manhattan College Journal of Business, Vol.15, 22-28. 
Loukidou, L., Loan-Clarke, J., Daniels, K. (2009). Boredom in the workplace: More than monotonous tasks. International of Journal of Management Reviews, Vol.11, Issue 4, 381-405.

Mäkikangas, A., Rantanen, J., Bakker, A., k, M.-L., Pulkkinen, L., Kokko, K. (2015). The Circumplex model of occupational well-being: Its relation with personality. Journal for Person- Oriented Research, Vol.1, 114-129.

Mann, S. (2007). The boredom boom. The Psychologist, Vol.20, No.2, 90-93.

Mitchell, T. R., Holtom, B. C. and Lee, T. (2001). How to keep your best employees: Developing an effective retention policy. The Academy of Management Executive, Vol.15, No.4, 96-109.

Mobley, W. H., Horner, S. O., Hollingsworth, A. T. (1978). An Evaluation of Precursors of Hospital Employee Turnover. Journal of Applied Psychology, Vol.63, No.4, 408-414.

Prinzel, L. J., Freeman, F. G. (1997). Task-specific sex differences in vigilance performance: Subjective workload and boredom. Perceptual and Motor Skills, Vol.85, 1195-1202.

Reijseger, G., Schaufeli, W.B., Peeters, M. C. W., Taris, T. W., van Beek, I., Ouweneel, E. (2013). Watching the paint dry at work: psychometric examination of the Dutch Boredom Scale. Anxiety, Stress \& Coping, Vol.26, No.5, 508-525.

Rhoades, L., Eisenberger, R. (2002). Perceived Organizational Support: A Review of the Literature. Journal of Applied Psychology, Vol.87, No.4, 698-714.

Sansone, C., Wiebe, D.J. and Morgan, C. (1999). Self-regulating interest: the moderating role of hardiness and conscientiousness. Journal of Personality, Vol.67, 701-733.

Sawin, D. A., Scerbo, M. W. (1995). Effects of instruction type and boredom proneness in vigilance: Implications for boredom and workload. Human Factors, Vol.37, $752-765$.

Smith, R. P. (1981). Boredom: A Review. Human Factors: The Journal of the Human Factors and Ergonomics Society, Vol.23, No.3, 329-340.

Spector, P.E., Fox, S., Penney, L.M., Bruursema, K., Goh, A., Kessler, S. (2006). The dimensionality of counterproductivity: Are all counterproductive behaviors created equal? Journal of Vocational Behavior, Vol.68, 446-460.

Tsai, C. J. (2016). Boredom at Work and Job Monotony: An Exploratory Case Study within the Catering Sector. Human Resource Development Quarterly, Vol.27, No.2, 207-236.

Van Hooff, M. L. M, Van Hooft, E. A. J. (2014). Boredom at work: Proximal and distal consequences of affective work-related boredom. Journal of Occupational Health Psychology, 19, 348-359.

Van Hoof, M. L. M., Van Hooft, E. A. J. (2016). Work-related boredom and depressed mood from a daily perspective: the moderating roles work centrality and need satisfaction. Work \& Stress, Vol.30, No.3, 209-227. 
Van Hoof, M. L. M., Van Hooft, E. A. J. (2017). Boredom at work: towards a dynamic spillover model of need satisfaction, work motivation, and work-related boredom. European Journal of Work and Organizational Psychology, Vol.26, No.1, 133148:

Watten, R.G., Sykversen, J.L. and Myhrer, T. (1995). Quality of life, intelligence and mood. Social Indicators Research, Vol.36, 287-299.

Weiss, H. M., Cropanzano, R. (1996). Affective events theory: A theoretical discussion of the structure, causes and consequences of affective experiences at work. Research in Organizational Behavior, Vol.18, 1-74.

Wiesner , M., Windle, M., Freeman, A. (2005). Work stress, substance use, and depression among young adult workers: An examination of main and moderator effect models. Journal of Occupational Health Psychology, Vol.10, 83-96. 